18 years, following the addition of carbamazepine, seizures were controlled, and pyridoxine was decreased to $100 \mathrm{mg}$ daily. MRI showed left mesial temporal sclerosis. Nerve conduction studies at 2 years revealed absent sensory action potentials and normal motor conduction. Sural nerve biopsy showed severe, axonal, sensory neuropathy. At 18 years, vibration sense in the feet was absent, position sense was decreased in the toes, pain sensation was impaired to the midcalf and in the fingers, tendon reflexes were absent, and plantar responses were flexor. His gait was ataxic. Sural, peroneal and median sensory nerve action potentials were absent. The sensory neuronopathy diagnosed at 2 years had not progressed or remitted at 18 years. (McLachlan RS, Brown WF. Pyridoxine dependent epilepsy with iatrogenic sensory neuronopathy. Can I Neurol Sci February 1995;22:50-51). (Reprints: Dr RS McLachlan, University Hospital, 339 Windermere Rd, London, Ontario N6A 5A5).

COMMENT. The authors explain the failure of pyridoxine to completely control the seizures in this patient by a combination of pyridoxinedependent epilepsy with complex partial seizures due to mesial sclerosis. Unusually high doses of pyridoxine were prescribed in this patient.

Doses as low as $50 \mathrm{mg}$ /day have caused neuropathy when continued for months or years. Individual susceptibility is also a factor in the occurrence of this side effect.

\title{
CRITICAL ILLNESS NEUROMUSCULAR DISEASE
}

Four children with critical illness neuromuscular disease following prolonged dependency on a ventilator are reported from the Departments of Neurology and Pediatrics, West Virginia University Health Sciences Center, Morgantown, and the Department of Medicine (Neurology), Memorial University of Newfoundland, St John's, Canada. One patient, a 15-year-old boy with septic shock, required ventilatory support and intermittent vecuronium for neuromuscular blockade. Extubation on day 8 was unsuccessful because of quadriparesis, with diffuse muscle atrophy, and absent reflexes. Muscle strength gradually returned over 3 months, but hyporeflexia persisted for $>1$ year. (Sheth RD, Bodensteiner JB et al. Critical illness neuromuscular disease in children manifested as ventilatory dependence. I Pediatr February 1995;126:259-61). (Reprints: Raj D Sheth MD, West Virginia University Health Science Center, Box 9180, Morgantown, WV 26506).

COMMENT. Critical-illness polyneuropathy, a complication of sepsis in adults, and a cause of difficulty in weaning from the ventilator, is covered in Progress in Pediatric Neurology II, 1994, pp275-276. The syndrome appears to be unusual in children.

\section{MUSCULAR FATIGUE IN DUCHENNE DYSTROPHY}

The fatigability of the anterior tibial muscle in 11 boys with Duchenne muscular dystrophy (DMD) was compared to that of controls at the California Pacific Medical Center and the University of California, San Francisco. The force generation of dystrophic muscle and compound muscle action potential amplitude were lower and relaxation time of tetanus was longer in patients than in controls at rest. During exercise, maximum voluntary contraction was better sustained, suggesting less central fatigue in DMD patients than in controls. (Sharma KR, Mynhier MA, Miller RG. Muscular fatigue in Duchenne muscular dystrophy. Neurology February 1995;45:306-310). (Reprints: Dr Khema R Sharma, University of Miami, Dept of Neurology, 1501 NW 9th Ave, Miami, FL 33136). 